\title{
Medicaid Expansion's Importance to Mental Health Care
}

\author{
Cameron Blazoski \\ Thomas Jefferson University, cameron.blazoski@students.jefferson.edu \\ Vittorio Maio, PharmD, MS, MSPH \\ Thomas Jefferson University, vittorio.maio@jefferson.edu
}

Follow this and additional works at: https://jdc.jefferson.edu/si_hs_2023_phase1

Part of the Public Health Commons

Let us know how access to this document benefits you

\section{Recommended Citation}

Blazoski, Cameron and Maio, PharmD, MS, MSPH, Vittorio, "Medicaid Expansion's Importance to Mental Health Care" (2021). Phase 1. Paper 9.

https://jdc.jefferson.edu/si_hs_2023_phase1/9

This Article is brought to you for free and open access by the Jefferson Digital Commons. The Jefferson Digital Commons is a service of Thomas Jefferson University's Center for Teaching and Learning (CTL). The Commons is a showcase for Jefferson books and journals, peer-reviewed scholarly publications, unique historical collections from the University archives, and teaching tools. The Jefferson Digital Commons allows researchers and interested readers anywhere in the world to learn about and keep up to date with Jefferson scholarship. This article has been accepted for inclusion in Phase 1 by an authorized administrator of the Jefferson Digital Commons. For more information, please contact: JeffersonDigitalCommons@jefferson.edu. 


\section{Jefferson}

\section{Medicaid Expansion's Importance to Mental Health Care}

Cameron Blazoski, Vittorio Maio* 


\section{Introduction \& Objective}

- Medicaid Expansion:

- Implemented: 39 states + D.C.

- Process of implementing: 2 states

- Not adopted: 12 states

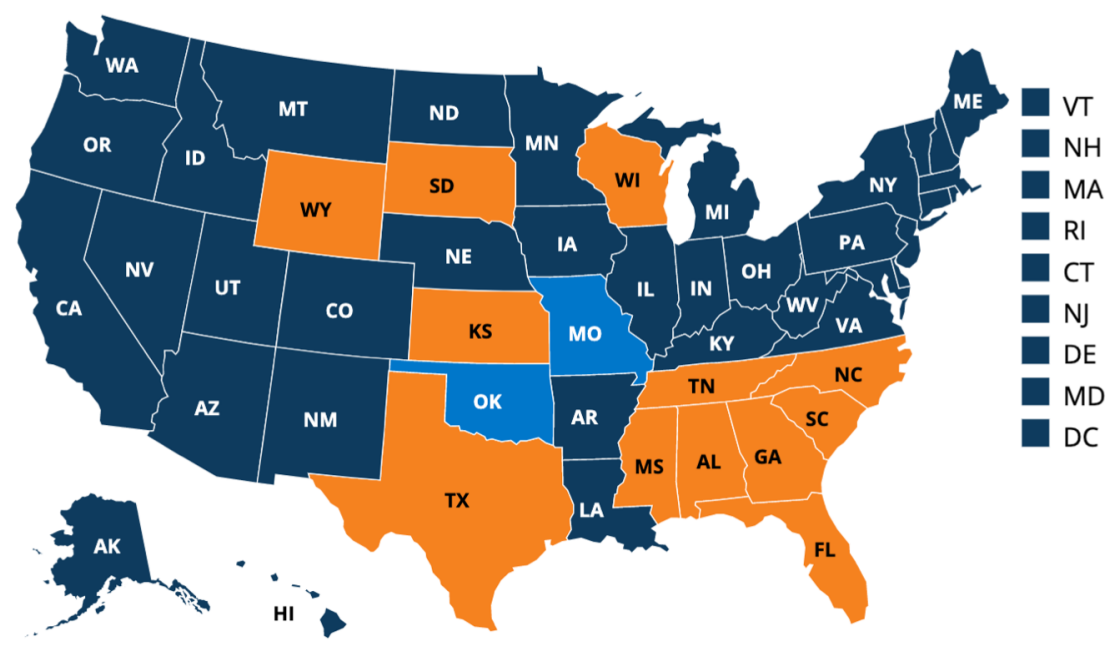

- Current research:

- Medicaid Expansion:

- $\rightarrow$ Decreased uninsured rate $^{2}$

- $\rightarrow$ Improved access, selfreported health, \& health outcomes $^{3}$

- Lacking data:

- Medicaid Expansion \& mental health

— Adopted and Implemented $\quad$ Adopted but Not Implemented $\quad$ Not Adopted

From "Status of State Medicaid Expansion Decisions: Interactive Map." Kaiser Family Foundation, 2 Feb. 2021, www.kff.org/medicaid/issue-brief/status-of-state-medicaid-expansion-decisions-interactive-map. 


\section{Introduction \& Objective}

- One in five U.S. adults lives with a mental health disorder (MHD) ${ }^{4}$

- 2019: 51.5 million

- $>50 \%$ of Americans with a MHD do not receive treatment ${ }^{5}$

Mental Health Services Received in Past Year Among U.S. Adults with Any Mental IIIness (2019)

Data Courtesy of SAMHSA

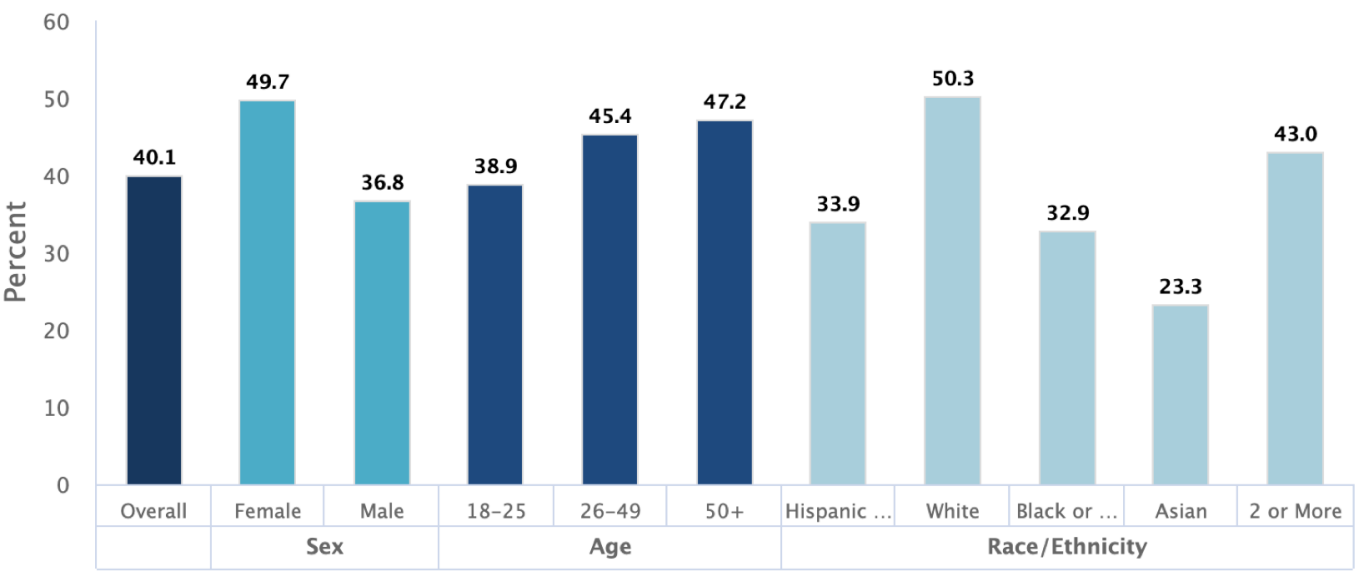

*Persons of Hispanic origin may be of any race; all other racial/ethnic groups are non-Hispanic.

Note: Estimates for Native Hawaiian / Other Pacific Islander and American Indian / Alaskan Native groups are not reported in the above figure due to low precision.

From Mental Health Information. National Institute of Mental Health. 


\section{Introduction \& Objective}

\section{What is the impact of Medicaid Expansion on mental health care?}

- Hypothesis: Medicaid Expansion will lead to...

- $\rightarrow$ Improved access

- $\rightarrow$ Improved outcomes 


\section{Methods}

- Study population

- Individuals w/MHDs/SUDs in expansion states vs. non-expansion states

- Target population \& stakeholders:

- Anyone involved in mental health care debate

- Politicians

- Federal government administrators

- State government administrators

- Governors of non-expansion states

- Governors of expansion states

- Mental health advocacy organizations 


\section{Methods}

- Data collection, review, analysis, and commentary

- 1. Data collection

- Systematic search in Google Scholar

- 2. Data analysis

- 3. Political analysis

- State of Medicaid Expansion

- State of ACA

- Current events + news
Voters in deep-red Missouri expand Medicaid under Obamacare

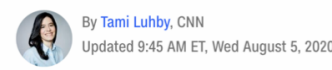

Ëbe Alew thork Eimes

Republican Leaders Want to End Obamacare. Their Voters Are Expanding It.

Oklahoma is the latest state where voters, in choosing to expand Medicaid, have delivered a rebuke to their elected officials. 


\section{Methods}

- Research on Access:

- Insurance rate

- Treatment rates

- Data sources:

- Publications - Health Affairs, Psychiatry Services, etc.

- Government publications SAMHSA, NIH

- Research on Outcomes

- Self-reported measures

- State-level data

- Data sources:

- Publications - Health Affairs, Psychiatry Services, etc.
- Mental Health National Statistics

- Comparing expansion states vs. non-expansion states

\section{Adults With AMI Who Are Uninsured} 2020

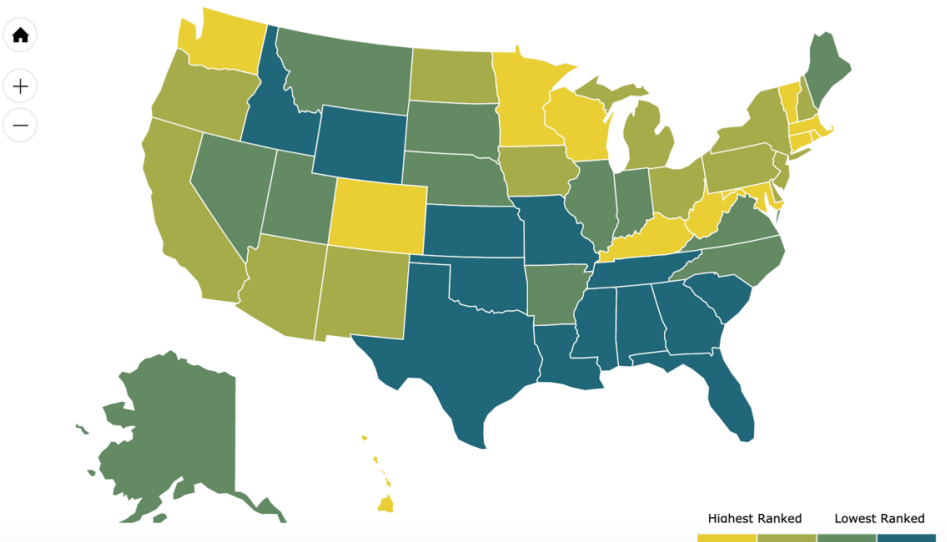
From Mental Health in America - Adult Data. Mental Health America.
https: / /www.mhanational.org/issues/mental-health-america-adult-data. Published 2020. Accessed February 29, 2020. 


\section{Results: Access to Care}

\section{Medicaid expansion was associated with...}

- Increase insurance rate among individuals with MHDs/SUDs ${ }^{6}$

- Increased treatment rates ${ }^{6}$

- Increased outpatient visits

- Increased medications
Exhibit 2 Percent of low-income adults with selected substance use disorders who were uninsured in 2008-15, in states that did and did not expand eligibility for Medicaid

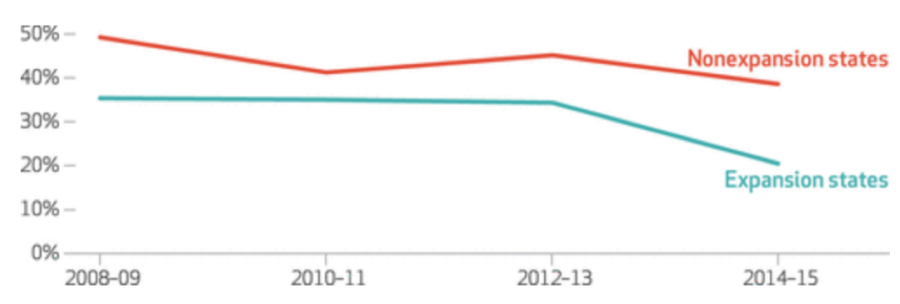

Exhibit 3 Percent of low-income adults with selected substance use disorders who received any substance use disorder treatment in the past year and who were covered by Medicaid in 2008-15, in states that did and did not expand eligibility for Medicaid

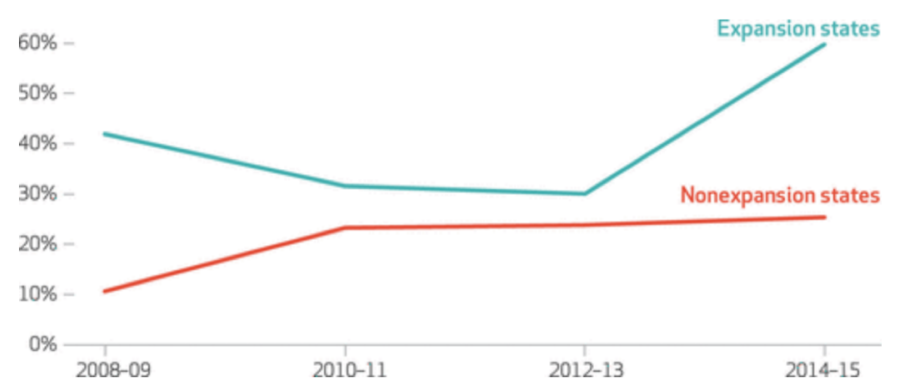

From Olfson M, Wall M, Barry CL, Mauro C, Mojtabai R. Impact Of Medicaid Expansion On Coverage And Treatment Of Low-Income Adults With Substance Use Disorders. Health Affairs. 2018;37(8):1208-1215. doi:10.1377/hlthaff.2018.0124

Medicaid Expansion $\rightarrow$ Improved access to mental health care 


\section{Results: Mental Health Outcomes}

Unadjusted and Adjusted Changes in Health Outcomes after Medicaid Expansion among Childless Adults with One or More Chronic Conditions $(n=79,306)$

\author{
Medicaid expansion was \\ associated with...
}

- Self-reported mental health

- Less poor mental health days ${ }^{7}$

- Less likely to report declines in mental health 8

- Higher quality of life

\author{
Medicaid Expansion $\rightarrow$ \\ Improved mental health outcomes
}

Jefferson

\begin{tabular}{|c|c|c|c|c|c|c|c|}
\hline Outcome & $\begin{array}{l}\text { Unadjusted pre- } \\
\text { ACA prevalence }\end{array}$ & $\begin{array}{r}\text { Unad } \\
\text { ACA }\end{array}$ & ed post- & $\begin{array}{c}\text { Unadjusted } \\
\text { difference in } \\
\text { differences }\end{array}$ & $\begin{array}{c}P \\
\text { value }\end{array}$ & $\begin{array}{l}\text { Adjusted } \\
\text { difference in } \\
\text { differences* }\end{array}$ & $\begin{array}{c}P \\
\text { value }\end{array}$ \\
\hline \multicolumn{8}{|c|}{ Poor mental health (days per month) } \\
\hline $\begin{array}{l}\text { Medicaid } \\
\text { expansion }\end{array}$ & 10.3 & 9.6 & & $\begin{array}{c}-1.2 \\
(-1.8,-0.64)\end{array}$ & $<0.001$ & $\begin{array}{c}-1.1 \\
(-1.6,-0.60)\end{array}$ & $<0.001$ \\
\hline \multicolumn{8}{|l|}{$\begin{array}{l}\text { Medicaid } \\
\text { expansion }\end{array}$} \\
\hline \multicolumn{8}{|c|}{$\begin{array}{l}\text { From Tipirneni R, Patel MR, Goold SD, et al. Association of Expanded Medicaid Coverage With Health } \\
\text { and Job-Related Outcomes Among Enrollees With Behavioral Health Disorders. PS. 2019;71 (1):4-11. } \\
\text { doi:10.1176/appi.ps.201900179 }\end{array}$} \\
\hline \multicolumn{8}{|c|}{$\begin{array}{l}\text { Exhibit } 4 \text { Changes in health status among Southern Community Cohort Study (SCCS) participants in Medicaid } \\
\text { expansion states from before to after expansion, by type of health status }\end{array}$} \\
\hline & & & & & & $\begin{array}{l}\text { Difference-in } \\
\text { differences }\end{array}$ & \\
\hline & $\begin{array}{l}\text { Percent experienc } \\
\text { change with expan }\end{array}$ & $\begin{array}{l}\text { ing } \\
\text { ision }\end{array}$ & $\begin{array}{l}\text { Counter } \\
\text { change }\end{array}$ & $\begin{array}{l}\text { ctual percent ex } \\
\text { thout expansion }\end{array}$ & riencing & Estimate & $\begin{array}{l}\text { Percentile } \\
\text { rank }\end{array}$ \\
\hline \multicolumn{8}{|l|}{ Mental health } \\
\hline No change & 37.8 & & 36.3 & & & 1.50 & 100.0 \\
\hline Improvement & 25.5 & & 24.9 & & & 0.62 & 97.8 \\
\hline Decline & 36.8 & & 38.9 & & & -2.10 & 0.2 \\
\hline
\end{tabular}

From Graves JA, Hatfield LA, Blot W, Keating NL, McWilliams JM. Medicaid Expansion Slowed Rates Of Health Decline For Low-Income Adults In Southern States. Health Affairs. 2020;39(1):67-76. doi:10.1377/hlthaff.2019.00929 

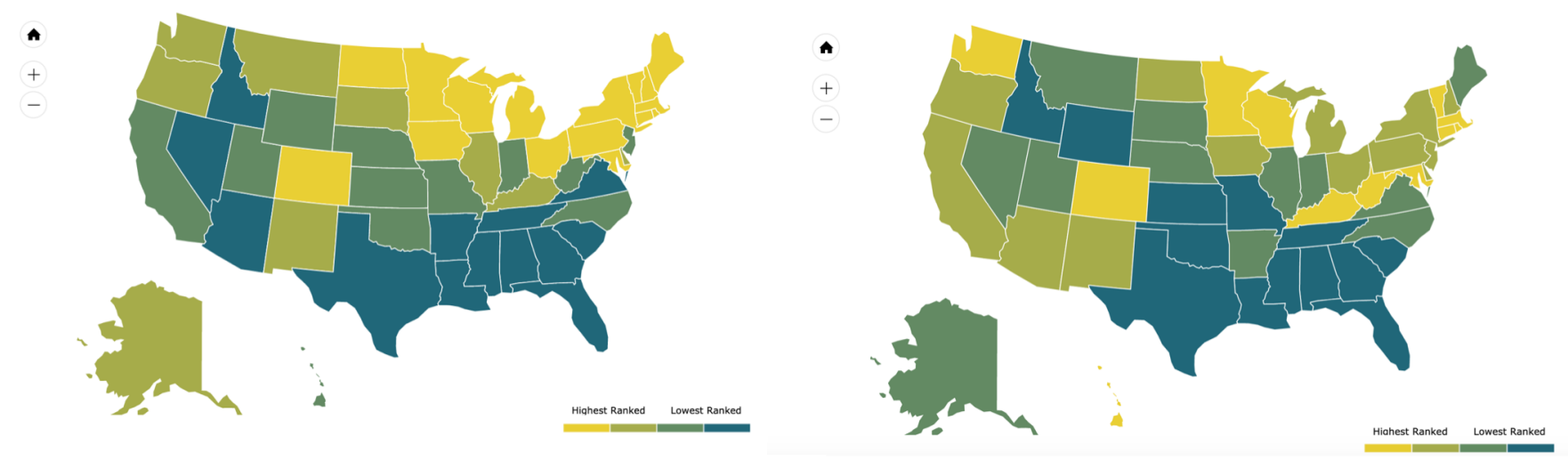

Adults With Disability Who Could Not See A Doctor Due To Costs 2020

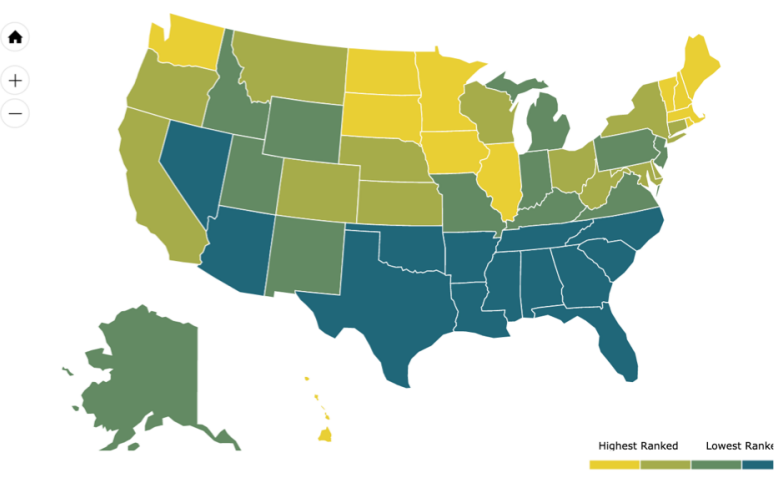

From Mental Health in America - Adult Data. Mental Health America. https: / / www.mhanational.org/issues/mental-health-america-adult-data. Published 2020. Accessed February 29, 2020.

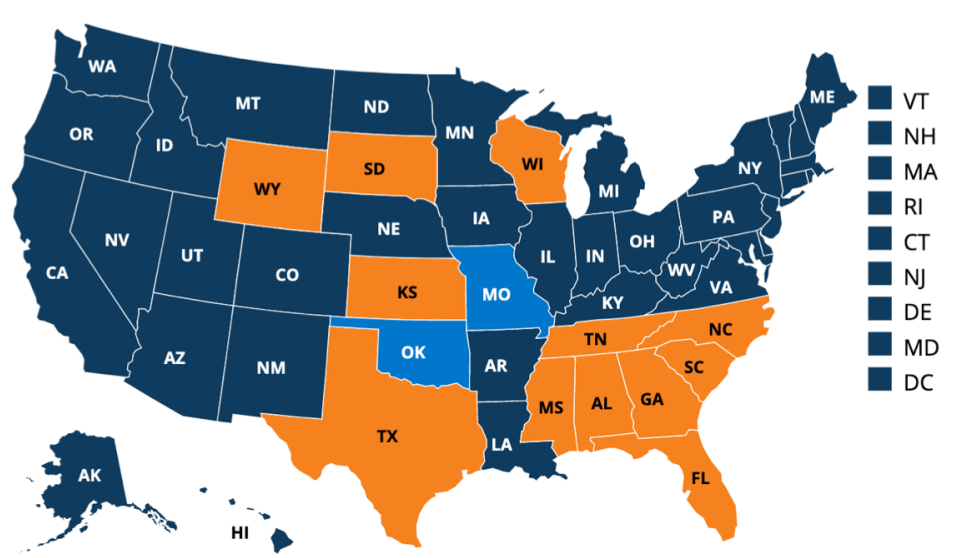

- Adopted and Implemented adopted but Not Implemented a Not Adopted

From "Status of State Medicaid Expansion Decisions: Interactive Map." Kaiser Family Foundation, 2 Feb. 2021, www.kff.org/medicaid/issue-brief/status-ofstate-medicaid-expansion-decisions-interactive-map.

There is a pattern among states that perform poorly in mental health rankings and their expansion status (and political leaning) 


\section{Conclusions}

Medicaid Expansion has improved access to mental health care and mental healthrelated outcomes, and further expansion would aid individuals with MHDs \& SUDs in non-expansion states. 


\section{Conclusions}

- Limitations:

- Limited data

- Federal vs. state statistics

- Possible improvements \& scope:

- Narrow scope - more SUD statistics than MHD

- Next steps:

- Wait on future research/statistics, then incorporate 


\section{Disclosures and Acknowledgements}

- I have nothing to disclose. 


\section{References}

1. "Status of State Medicaid Expansion Decisions: Interactive Map." Kaiser Family Foundation, 2 Feb. 2021, www.kff.org/medicaid/issue-brief/status-of-state-medicaid-expansion-decisions-interactive-map.

2. Garfield R, Orgera K, Damico A. The Uninsured and the ACA: A Primer - Key Facts about Health Insurance and the Uninsured amidst Changes to the Affordable Care Act - How many people are uninsured? The Henry J. Kaiser Family Foundation. https://www.kff.org/report-section/the-uninsured-and-the-aca-a-primer-key-facts-about-health-insurance-and-the-uninsuredamidst-changes-to-the-affordable-care-act-how-many-people-are-uninsured/. Published May 13, 2019. Accessed April 6, 2020.

3. Guth M, Garfield R, Rudowitz R. The Effects of Medicaid Expansion under the ACA: Updated Findings from a Literature Review. The Henry J. Kaiser Family Foundation. https://www.kff.org/medicaid/report/the-effects-of-medicaidexpansion-under-the-aca-updated-findings-from-a-literature-review/. Published March 17, 2020. Accessed April 6, 2020.

4. Mental Health Information. National Institute of Mental Health. https://www.nimh.nih.gov/health/statistics/mentalillness.shtml. Accessed February 28, 2020.

5. Mental Health in America - Adult Data. Mental Health America. https://www.mhanational.org/issues/mental-healthamerica-adult-data. Published 2020. Accessed February 29, 2020.

6. Olfson M, Wall M, Barry CL, Mauro C, Mojtabai R. Impact Of Medicaid Expansion On Coverage And Treatment Of LowIncome Adults With Substance Use Disorders. Health Affairs. 2018;37(8):1208-1215. doi:10.1377/hlthaff.2018.0124

7. Tipirneni R, Patel MR, Goold SD, et al. Association of Expanded Medicaid Coverage With Health and Job-Related Outcomes Among Enrollees With Behavioral Health Disorders. PS. 2019;71(1):4-11. doi:10.1176/appi.ps.201900179

8. Graves JA, Hatfield LA, Blot W, Keating NL, McWilliams JM. Medicaid Expansion Slowed Rates Of Health Decline For LowIncome Adults In Southern States. Health Affairs. 2020;39(1):67-76. doi:10.1377/hlthaff.2019.00929 


\section{Questions?}




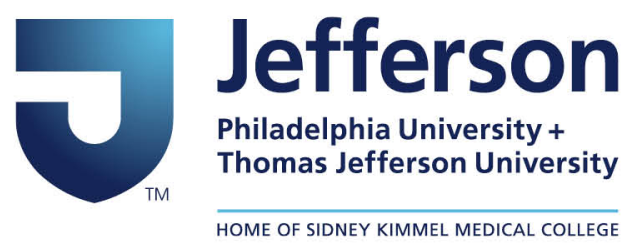

